Tropical Journal of Pharmaceutical Research March 2017; 16 (3): 689-696

ISSN: $1596-5996$ (print); 1596-9827 (electronic)

(C) Pharmacotherapy Group, Faculty of Pharmacy, University of Benin, Benin City, 300001 Nigeria.

All rights reserved.

Available online at http://www.tjpr.org

Original Research Article

http://dx.doi.org/10.4314/tjpr.v16i3.26

\title{
Opinions of pharmacists and herbalists on herbal medicine use and receiving herbal medicine education in Jordan
}

\author{
Iman A Basheti ${ }^{1 \star}$, Eman R Elayeh², Dalal B Al Natour DB ${ }^{1}$ and Sami Saqf el \\ Hait $^{3}$ \\ ${ }^{1}$ Department of Clinical Pharmacy and Therapeutics, Faculty of Pharmacy, Applied Science Private University, ${ }^{2}$ Department of \\ Biopharmaceutics and Clinical Pharmacy, Faculty of Pharmacy, University of Jordan, Amman, Jordan, ${ }^{3}$ Department of Quality \\ Assurance, Baxter Company Limited, Dammam, Saudi Arabia
}

*For correspondence: Email: dr_iman@asu.edu.jo; Tel: +962 799048 003; Fax: +96265515017

Received: 31 August 2016

Revised accepted: 18 December 2016

\begin{abstract}
Purpose: To explore the beliefs of herbalists and community pharmacists on receiving educational courses in herbal medicine (HM) use by patients at pharmacy schools.

Methods: This cross-sectional study was conducted in 2014. Herbalists $(n=48)$ and pharmacists $(n=$ 163) were randomly recruited into the study. Demographic data, beliefs on HM use by patients, and willingness to attend educational courses were collected using a validated questionnaire and one-onone interviews.

Results: The majority of the herbalists ( $n=37,77.1 \%)$ believed that HMs are highly used in Jordan as alternative or add-on therapy to conventional medications, and the majority $(n=39,81.3 \%)$ reported that they need to be educated on HM use by a professional organization. More than $80 \%$ of the pharmacists believed that they need to be experts on HM use and should apply pharmaceutical care for patients buying registered HMs at their pharmacies; a significantly higher proportion of female pharmacists $(p=0.04)$ agreed with this concept compared to male pharmacists.

Conclusion: Both herbalists and pharmacists showed interest in attending educational courses on HM use at pharmacy schools to improve their ability to serve their patients.
\end{abstract}

Keywords: Herbalists, Community pharmacists, Herbal medicine, Pharmaceutical care

Tropical Journal of Pharmaceutical Research is indexed by Science Citation Index (SciSearch), Scopus, International Pharmaceutical Abstract, Chemical Abstracts, Embase, Index Copernicus, EBSCO, African Index Medicus, JournalSeek, Journal Citation Reports/Science Edition, Directory of Open Access Journals (DOAJ), African Journal Online, Bioline International, Open-J-Gate and Pharmacy Abstracts

\section{INTRODUCTION}

Herbal medicines (HMs) have been used therapeutically for thousands of years and continue to be widely used worldwide due to their high acceptance by patients, perceived efficacy, relative safety, and low cost [1-3]. A majority of people perceive HMs as natural and therefore safe. Patients also appreciate their active role and perceived autonomy in choosing HM [1]. However, concerns about the quality, contamination, safety, and efficacy of many HMs continue to be of high concern [2,4]. Potential side effects and interactions between HMs and conventional drugs have been documented [5], but a patient's request for a licensed HM can be approved if there is no conventional concomitant co-medication that is known or expected to interact, no contra-indication, and no other conventional treatment with a better benefit-risk ratio [6].

Among health care professionals, pharmacists are in a unique position to provide evidencebased information regarding $\mathrm{HMs}$ and help patients and customers make safe decisions about their use [7]. Furthermore, HMs are 
increasingly available in community pharmacies, and many consumers believe that pharmacists are knowledgeable in this area and can reliably provide the needed counseling [7]. Herbalists on the other hand, continue to be the main source of education regarding $\mathrm{HMs}$ for consumers $[7,8]$. However, both pharmacists and herbalists have suboptimal knowledge regarding important aspects of HM use $[9,10]$.

HM use is very common in the Arab world, and Jordan is no exception [11]. Herbal remedies are available to people living in Jordan through the herbal medicament shops, while the registered pre-packaged HMs are available at community pharmacies. Many patients in Jordan suffering from chronic medical conditions concurrently use conventional treatments and alternative $\mathrm{HMs}$ [12]. Bridging the gap between pharmacists and herbalists is important to ensure patient safety. Attending educational courses on HMs can pave the way towards productive interprofessional relationships and better patient care.

The aims of this study are to characterize the perceived roles of herbalists and community pharmacists in Jordan regarding patient HM use and to investigate the willingness of herbalists to attend educational HM courses at pharmacy schools.

\section{METHODS}

This cross-sectional study was conducted in 2014 in Amman (the capital of Jordan) and Zarqa (the second largest city in Jordan). This study was approved by the Scientific Research Ethical Committee at the Faculty of Pharmacy, Applied Science Private University (ethics approval no. 10/2014/2015). Herbalists working in HM stores and pharmacists working in community pharmacies were recruited randomly. Socioeconomic levels of the areas from where the participants were recruited were identified. A two-part face-to-face questionnaire (part $A$ for herbalists and part $B$ for community pharmacists) was designed and validated to meet the aims of this study.

\section{Herbalists}

The herbalist portion of the questionnaire was designed to collect their demographic information including gender, age, practicing years, reason for choosing the profession, and their work address (to identify the area's socioeconomic status). The second part consisted of questions investigating the most common gender and age range of their customers and history regarding HM educational courses. Five-point Likert scale questions were written to investigate their interest in their profession, their beliefs regarding the importance of $\mathrm{HM}$ use in Jordan, their interest in attending interprofessional educational courses on HM with pharmacists, and whether they thought pharmacists could help optimize their profession. Only one herbalist from each herbal shop recruited into the study completed the questionnaire.

Cognitive bias can cause social desirability, where respondents answer questions in a way that is not fully in accordance with their true beliefs. The researcher who conducted the study was instructed about this issue to help obtain accurate results, and participants were not informed of the researcher's profession (pharmacist) or the true nature of the study.

Questionnaire face validity was assessed by five clinical professional experts. The study was then piloted by visiting herbalists from low and high socioeconomic status areas $(n=10$ from each socioeconomic area); we collected their feedback on the questionnaire to ensure the clarity and suitability of questions. The views and comments of the herbalists were considered by the research team and incorporated as appropriate into the final version of the questionnaire. Answered questionnaires completed during the pilot study were excluded from the final analysis.

\section{Community pharmacists}

The pharmacist portion of the questionnaire included questions regarding the demographics and work characteristics of the community pharmacists. The beliefs of pharmacists regarding the public's use of HM in Jordan and their role in this area were investigated. Fivepoint Likert scale questions were used to assess pharmacist beliefs. The questionnaire was first completed by graduate pharmacy students $(n=$ 10) to test for question clarity and suitability. Verified comments provided by the students were incorporated where appropriate into the final questionnaire. Face validity was evaluated by five clinical professional experts. The researcher who conducted this part of the study was told about the effects of cognitive bias as was done for the herbalist portion of the study.

\section{Data analysis}

Participants' responses were encoded, and the data were analyzed using Statistical Package for the Social Sciences software (SPSS Inc, version 17, Chicago, IL, US). Descriptive analysis was carried out to determine the proportion of herbalists and pharmacists who selected each of 
the answers for each of the questions in the questionnaire form (valid percentages are reported). Chi square tests were used to identify significant differences among the participants' responses, with significance defined as $p \leq 0.05$.

Multiple linear regression analysis was performed to determine the predictors of the opinion of herbalists regarding the need to be educated on HM use and their side effects by a professional organization. The dependent variable was the agreement of herbalists with this statement. Independent variables included age, practicing years, socioeconomic status of their work area, and their opinion regarding perceiving a role for pharmacists in helping them enhance their profession.

\section{RESULTS}

\section{Responses of herbalists}

A convenience sample of herbalists $(n=48)$ agreed to complete the questionnaire, and only 2 refused to conduct the interview (response rate, $96.0 \%$ ). All of the herbalists were male, aged (mean \pm SD) $40.6 \pm 12.48$ with $16.2 \pm 9.01$ years of experience. The locations of the herbalist shops were distributed between low (39.6\%) and high $(60.4 \%)$ socioeconomic status areas.

Herbalists reported that most of their customers are females $(n=37,78.7 \%)$, with typical age ranges of 36 to 45 years $(n=24,54.5 \%)$ and 26 to 35 years $(n=10,22.7 \%)$.
Out of those who answered the question regarding whether they like their profession or not $(n=28)$, a majority said yes $(n=22,78.6 \%)$ giving different reasons including: it is their father's profession $(\mathrm{n}=6,21.4 \%)$, they appreciate the trust that customers give them (n $=3,10.7 \%)$, HMs are natural and safe $(n=5$, $17.8 \%)$, working with $\mathrm{HMs}$ is interesting ( $\mathrm{n}=8$, $28.6 \%$ ), their profession provides them with the capacity to help people $(n=4,14.2 \%)$, and it is financially rewarding $(n=2,7.1 \%)$.

A majority of the herbalists ( $\mathrm{n}=37,77.1 \%$ ) believed that HMs are highly used in Jordan as alternative or add-on therapies to conventional medications for acute and chronic medical conditions (Figure 1).

All of the herbalists who answered the question "Have you been invited to attend an educational course on HM use in the past year in Amman" ( = 28), answered "No." One of them reported attending a course outside of Jordan.

A large proportion of herbalists $(n=39,8 \%)$ reported that they need to be educated on $\mathrm{HM}$ use and their side effects by a professional organization (Table 1). Most of the herbalists were open to completing short and long educational courses on HM use and their side effects prepared by pharmacy schools (interprofessional workshops) to improve their ability to serve their customers (Table 1).

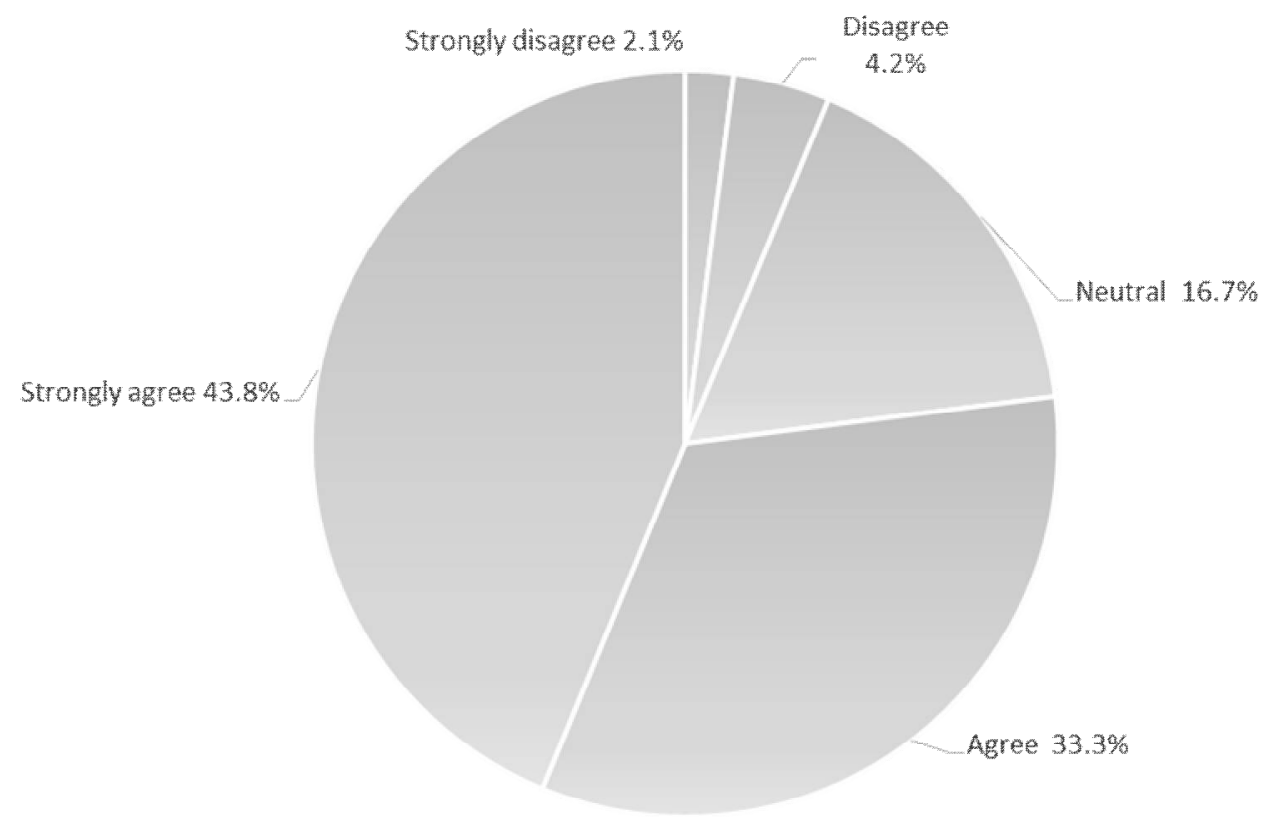

Figure 1: Proportion of herbalists $(n=48)$ who believe that HMs are highly used in Jordan as alternative or add-on therapies to conventional medications used in acute and chronic medical conditions 
Table 1: Beliefs of herbalists $(n=48)$ regarding the importance of receiving educational courses on herbal medicine use

\begin{tabular}{|c|c|c|c|c|c|}
\hline \multirow[b]{2}{*}{ Question } & \multicolumn{5}{|c|}{ Views of herbalists, $\mathbf{n}(\%)$} \\
\hline & $\begin{array}{c}\text { Strongly } \\
\text { Agree }\end{array}$ & Agree & Neutral & Disagree & $\begin{array}{l}\text { Strongly } \\
\text { Disagree }\end{array}$ \\
\hline $\begin{array}{l}\text { Herbalists need to be educated on herbal } \\
\text { medicine use and their side effects by a } \\
\text { professional organization }\end{array}$ & $\begin{array}{c}26 \\
(54.2)\end{array}$ & $\begin{array}{c}13 \\
(27.1)\end{array}$ & $\begin{array}{c}2 \\
(4.2)\end{array}$ & $\begin{array}{c}7 \\
(14.6)\end{array}$ & $\begin{array}{c}0 \\
(0.0)\end{array}$ \\
\hline $\begin{array}{l}\text { You would like to study a short course ( } 2 \text { to } 6 \\
\text { weeks) on herbal medicine use and their side } \\
\text { effects prepared by pharmacy schools to be } \\
\text { able to serve your customers better }\end{array}$ & $\begin{array}{c}19 \\
(39.6)\end{array}$ & $\begin{array}{c}11 \\
(22.9)\end{array}$ & $\begin{array}{c}4 \\
(8.3)\end{array}$ & $\begin{array}{c}11 \\
(22.9)\end{array}$ & $\begin{array}{c}4 \\
(8.3)\end{array}$ \\
\hline $\begin{array}{l}\text { You would like to study a longer course (example } \\
12 \text { to } 24 \text { weeks) on herbal medicine use and } \\
\text { their side effects prepared by pharmacy schools } \\
\text { to be able to serve your customers better }\end{array}$ & $\begin{array}{c}18 \\
(37.5)\end{array}$ & $\begin{array}{l}10 \\
(20.8)\end{array}$ & $\begin{array}{c}3 \\
(6.3)\end{array}$ & $\begin{array}{c}13 \\
(27.1)\end{array}$ & $\begin{array}{c}3 \\
(6.3)\end{array}$ \\
\hline
\end{tabular}

Table 2: Summary of the regression model obtained for the dependent variable, the opinion of herbalists regarding the need to be educated on HM use and side effects by a professional organization $(n=48)$.

\begin{tabular}{lccc}
\hline Variable & Beta & t & $\boldsymbol{P}$-value \\
\hline Age & -0.109 & -0.377 & 0.713 \\
Practicing years & 0.335 & 1.204 & 0.252 \\
$\begin{array}{l}\text { Work socioeconomic status } \\
\begin{array}{l}\text { Opinion regarding perceiving a role for } \\
\text { pharmacists in helping them enhance their }\end{array} \\
\text { profession was not significant. }\end{array}$ & 0.701 & 3.401 & $\mathbf{0 . 0 0 5}$ \\
\hline
\end{tabular}

A significantly larger proportion of herbalists working in areas with high socioeconomic status agreed to receive educational courses on $\mathrm{HM}$ use compared to herbalists working in low socioeconomic status areas $(p=0.013$, chi square test).

A majority of the herbalists ( $81.5 \%$ ) perceived a role for pharmacists in helping them enhance their profession by increasing their interprofessional collaboration to better serve their customers.

Multiple linear regression modeling indicated that work socioeconomic status was the only variable significantly associated with the opinion of herbalists regarding the need to be educated on HM use and their side effects by a professional organization (The overall fit of the model was $R^{2}$ $=0.568, p=0.029$; Table 2); age, practicing years, and opinion regarding perceiving a role for the pharmacists in helping them enhance their profession were not significant.

Table 2 shows the output from a multivariable regression analysis in which the dependent variable was "the opinion of herbalists regarding the need to be educated on HM use and their side effects by a professional organization". "Beta" is the standardized regression coefficient. The overall fit of the model was $\mathrm{R} 2=0.568, p=0.029$.

\section{Responses of community pharmacists}

A total of 163 pharmacists were recruited into this study (giving a response rate of $90.6 \%$ ), with 54.8 $\%(n=86)$ being females. The mean $( \pm S D)$ age of participants was $33.1 \pm 9.75$, and they had 9.7 \pm 8.44 years of pharmacy experience.

The majority had a Bachelor's in Pharmacy degree $(n=149,93.1 \%)$, while only $5.6 \%(n=9)$ had a Master's degree, and 1 had a Doctor of Philosophy degree. The majority of pharmacists ( $\mathrm{n}$ $=129,83.8 \%$ ) completed their pharmacy education in Jordan.

The pharmacy average daily sales were distributed into three categories: less than 200 prescriptions per day ( $n=68,48.2 \%), 200$ to 400 prescriptions per day $(n=44,31.2 \%)$, and more than 400 prescriptions per day $(n=29,20.6 \%)$.

Most pharmacists reported selling registered HMs in their pharmacies $(n=121,87.7 \%)$. More than half of the respondents $(n=84,51.5 \%)$ agreed/strongly agreed that patients in Jordan use registered HMs found in the pharmacies as alternatives to conventional medications (19.6\% were not sure, while $28.8 \%$ disagreed or strongly disagreed). Respondents agreed or strongly agreed with the concept that inherited culture regarding the safety and efficacy of HM in Jordan is an important cause for people's use of HM ( $n=$ $129,87.8 \%)$. 


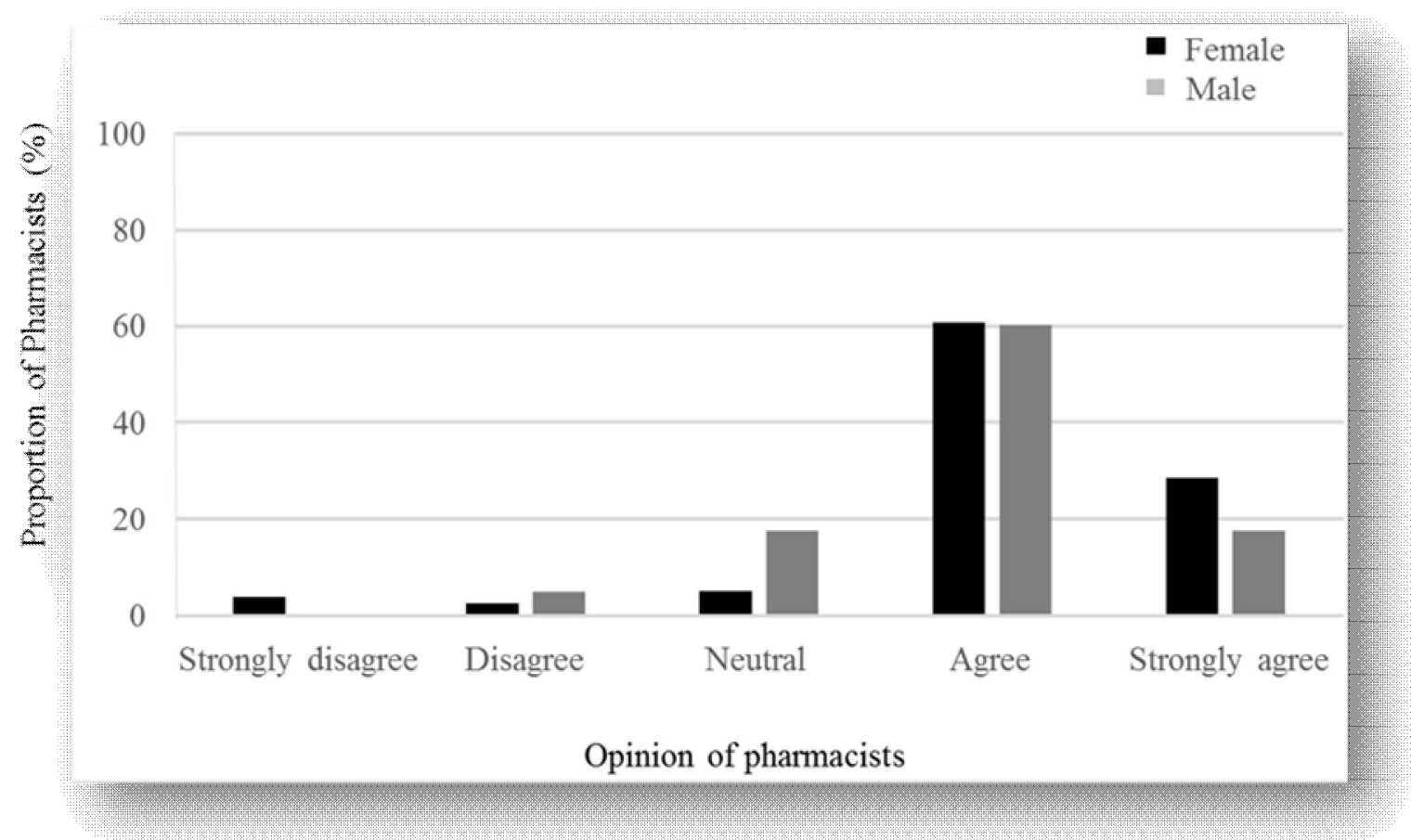

Figure 2: Agreement of pharmacists with the importance of applying pharmaceutical care for customers buying $\mathrm{HM}$ at their pharmacies. There were significant differences between females and males.

Eighty percent of respondents believed that community pharmacists need to be experts on $\mathrm{HM}$ and should have the ability to effectively counsel patients on their safe and effective use.

Most pharmacists ( $n=121,84.0 \%$ ) agreed with the importance of applying pharmaceutical care for patients buying registered $\mathrm{HMs}$ at the pharmacies. A significantly higher proportion of female pharmacists ( $p=0.04$, chi square test) agreed with this concept compared to male pharmacists (Figure 2).

\section{DISCUSSION}

This observational cross-sectional study explored herbalist and pharmacist views regarding $\mathrm{HM}$ use in Jordan and interest in attending educational courses prepared by pharmacy schools. This investigation paves the way toward the development of interprofessional educational courses on HM use for both herbalists and pharmacists given that both showed interest in attending continuous education courses with the aim to better serve their patients. From the patients' perspective, patients from Jordan and the UAE reported that they primarily depend on the herbalist, followed by the pharmacist (Jordan), and general practitioner (UAE) for advice on their HM use [8].

Pharmacists reported high sales of registered $\mathrm{HMs}$ at their community pharmacies, which is similar to what was reported in the UAE [13] and Palestine [14]. Pharmacists believe that Jordanians use HMs due to beliefs in their safety and efficacy. In a study of 2,000 patients visiting community pharmacies in Amman, Jordan, about half reported using $\mathrm{HM}$, and many (77.0 \%) believed that HMs were a safer alternative to conventional medications [7]. Patients from Palestine, UAE, and Saudi Arabia also consider HMs to be efficacious and safer than conventional medicines $[15,16]$.

The study revealed that most customers visiting herbalists for a consultation and purchase of $\mathrm{HM}$ products are women of childbearing age. Unlicensed HMs may be sourced from suppliers who provide no assurances as to standards [3]. In general, HMs should be employed carefully during pregnancy to prevent side effects, especially during the first trimester [3,17]. Educational courses focusing on HM use during pregnancy and lactation are vital for both herbalists and pharmacists.

It is expected that socioeconomic status differences affect results of research in the traditional HM area [7]. This study sheds light on this fact, as significantly more herbalists working in high socioeconomic status areas in Amman were interested in receiving educational courses on $\mathrm{HM}$ compared to herbalists working in low socioeconomic status areas. Differences were also reported previously for patients living in 
Amman, as those living in high socioeconomic status areas reported more attempts to use HM compared to patients living in low socioeconomic status areas (70.7 vs. $64.2 \%, p<0.001)$ [7].

Due to the high use of HM in Jordan, community pharmacists should have the ability to counsel patients on their proper use. In order to perform their role efficiently, pharmacists need to be knowledgeable on all aspects of $\mathrm{HM}$ pharmacology and therapeutics [13]. The lack of knowledge on registered HMs among pharmacists can lead to poor-quality care including failure to refer the patient back to their doctor when required, failure to form a rationale for treatment, failure to explain the treatment, and failure to consider the risks of HM-drug interactions [3]. The findings of this study are promising, as pharmacists believed that it is important to deliver pharmaceutical care to their patients while purchasing registered $\mathrm{HM}$ at their pharmacies. Advertising campaigns regarding the importance of this topic would be beneficial to draw the attention of the community pharmacists to the importance of their role.

Jordan Food and Drug Association (JFDA) herbal drug laws and regulations were established in 2001 and are partly similar to those governing conventional pharmaceuticals, with $\mathrm{HMs}$ regulated as prescription medicines, over-the-counter medicines, and for selfmedication [18]. HMs are sold in pharmacies as over-the-counter and prescription medicines without restriction. A post-marketing surveillance system that includes adverse effect monitoring was established in 2002 [18]. Such strategies applied in the country are commendable, and we further recommend the development of a special guiding manual including the JFDA-approved herbal products sold in community pharmacies with evidence-based $\mathrm{HM}$ practice. A second recommendation would be to run an educational public campaign regarding the safe use and misuse of the most commonly used HMs in the country. Finally, focusing on clinical research in the area of $\mathrm{HM}$ use and supporting its establishment would be highly valuable. A successful approach in this area is found in the United States, where government-funded agencies such as the Office of Dietary Supplements within the National Institutes of Health (NIH) and the National Center of Complementary and Alternative Medicine (NCCAM) educate the public about natural treatments and HMs and support clinical research to ensure their efficacy and safety [19].

A cornerstone in sustaining the ability of pharmacists to counsel patients on HM use is the undergraduate pharmacy curriculum. Revising the existing local pharmacy curriculum and providing training for pharmacy graduates on clinical phytotherapy is recommended [13]. Fortunately, this is the case in Jordan, as most practicing pharmacists in the community setting receive extensive education in this domain at the undergraduate B.Pharm and Pharm.D degree levels [11]. The pharmacy curriculum in most Jordanian universities has one or two pharmacognosy and phytochemistry courses. The Pharm.D program, provided by two public universities in the country, incorporates an additional course on the chemistry of medicinal plants including different complementary and alternative therapies, with their JFDA-approved therapeutic indications, dosage regimens, and precautions for use. Providing such advanced courses to the pharmacy graduates in the country provides them with a solid background in the area of HMs use and their side effects.

It was interesting to find that significantly more female than male pharmacists agreed on the need to deliver pharmaceutical care services regarding $\mathrm{HM}$. This might be due to the fact that female pharmacists are more aware of the cultural aspects of HM use in Jordan, since that as reported by the herbalists, females generally use HMs more frequently. Hence, educational courses in this area should have a special focus on male pharmacists.

It was promising to find that herbalists have interest in receiving educational courses on HM use at pharmacy schools in Jordan. Herbalists in the United Kingdom continue to practice based on tradition and personal experience [20]. Good professional standards are encouraged through voluntary accreditation or self-regulation schemes [20]. There are several programs in the United Kingdom and United States that offer a full 2 to 3-year courses of study in clinical HM [21]. Many of these programs also offer some degree of on-site clinical training. In the UK, the National Institute of Medical Herbalists has historically managed its own accreditation process in the area of herbalist education [22] To be accredited, herbalists obtain a bachelor degree, such as the B.Sc. (Honors) to be able to practice [22]. An example is the B.Sc. Herbal Medicine (Honors) degree offered by Westminster University (located in London, UK) [22]. Postgraduate diplomas and master courses are also available for herbalists interested in further HM studies and specialization [22]. Providing education to herbalists and pharmacists would be useful to guarantee the successful concurrent use of $\mathrm{HM}$ and conventional medicines $[3,4]$. It would be of great 
benefit to implement different strategies in Jordanian universities in coordination with pharmacy faculty members to offer interprofessional courses that focus on HM use and practice.

\section{Limitations of the study}

The major limitation of this cross-sectional study primarily is the small sample size. Furthemore, conventional sample technique could have produced a biased sample, thus limiting the generalization of the results. This study is a mere observation of the views of herbalists and pharmacists in Amman, the capital of Jordan, making it liable to social desirability bias.

\section{CONCLUSION}

HM use is prevalent among patients in Jordan. Pharmacists and herbalists are aware of this, and both types of professionals welcome educational courses conducted at pharmacy schools to enhance their knowledge of $\mathrm{HM}$ pharmacological activities and side effects to improve their ability to serve their customers. Future studies should investigate ways to improve the evidence-based practice of both professions in the area of HM.

\section{DECLARATIONS}

\section{Acknowledgement}

The authors are grateful to Applied Science Private University Amman, Jordan for the financial support granted for this research project (Grant no. DRGS-2014-2015-205). The authors would like to thank all pharmacists, herbalists and pharmacy students who participated in this study. We acknowledge Dr. Wamid Altalib, pharmacist Ferial Alsabelah, and analyst Mohamad Ghabayn for their help in this research study.

\section{Conflict of Interest}

No conflict of interest associated with this work.

\section{Contribution of Authors}

The authors declare that this work was done by the authors named in this article and all liabilities pertaining to claims relating to the content of this article will be borne by them.

\section{Open Access}

This is an Open Access article that uses a funding model which does not charge readers or their institutions for access and distributed under the terms of the Creative Commons Attribution License (http://creativecommons.org/licenses/by 14.0) and the Budapest Open Access Initiative (http://www.budapestopenaccessinitiative.org/rea d), which permit unrestricted use, distribution, and reproduction in any medium, provided the original work is properly credited.

\section{REFERENCES}

1. Joos S, Glassen K, Musselmann B. Herbal Medicine in Primary Healthcare in Germany: The Patient's Perspective. Evid Based Complement Alternat Med. 2012; 2012 (Article ID 294638): 1-10.

2. Cock IE. The safe usage of herbal medicines: counterindications, cross-reactivity and toxicity. Phcog Commn. 2015; 5(1): 2-38.

3. UK Herbal Medicines Advisory Committee (HMAC) for the Herbal Medicines and Practitioners Working Group (HMPWG). Safety rahmarote. [accessed on 2017 Jan 6]. Available from: https://www.gov.uk/government/ uploads/system/uploads/attachment_data/file/545681/H MAC___HerbalsafetyOctober2014Final.pdf.

4. Job KM, Kiang TK, Constance JE, Sherwin CM, Enioutina EY. Herbal medicines: challenges in the modern world. Part 4. Canada and United States. Expert Rev Clin Pharmacol. 2016; 9(12):1597-1609.

5. Saad B, Azaizeh H, Abu-Hijleh G, Said O. Safety of traditional Arab herbal medicine. Evid Based Complement Alternat Med. 2006; 3(4):433-439.

6. Morike $\mathrm{K}$, Gleiter $\mathrm{CH}$. [Herbal medicines: when to use or not to use?]. Internist (Berl). 2014; 55(11):1361-1366.

7. Qunaibi E, Basheti IA, Hamadi SA, Bulatova NR, Shanah A, Abu-Gharbieh E. Effect of Divergence in Patients' Socioeconomic Background on their Perspective of the Role of the Community Pharmacist in Amman, Jordan. Trop J Pharm Res. 2013; 12(2): 247-253.

8. Basheti IA, Qunaibi EA, Hamadi SA, Abu-Gharbieh E, Saleh S, AbuRuz S, et al. Patient Perspectives of the Role of the Community Pharmacist in the Middle East: Jordan, United Arab Emirates and Iraq. Pharmacol Pharm. 2014; 5: 588-599.

9. Abu-Irmaileh BE, Afifi FU. Herbal medicine in Jordan with special emphasis on commonly used herbs. $J$ Ethnopharmacol. 2003; 89(2-3): 193-197.

10. Oshikoya KA, Oreagba IA, Ogunleye OO, Oluwa $R$, Senbanjo IO, Olayemi SO. Herbal medicines supplied by community pharmacies in Lagos, Nigeria: pharmacists' knowledge. Pharm Pract (Granada). 2013; 11(4): 219-227.

11. Issa RI, Bashetil IA. Herbal Products Use Among Chronic Patients and its Impact on Treatments Safety and Efficacy: A Clinical Survey in the Jordanian Field. Trends Med Res. 2017; 12: 32-44. 
12. Wazaify M, Alawwa I, Yasein N, Al-Saleh A, Afifi FU. Complementary and alternative medicine (CAM) use among Jordanian patients with chronic diseases. Complement Ther Clin Pract. 2013; 19(3): 153-157.

13. Fahmy SA, Abdu S, Abuelkhair M. Pharmacists' attitude, perceptions and knowledge towards the use of herbal products in Abu Dhabi, United Arab Emirates. Pharm Pract (Granada). 2010; 8(2): 109-115.

14. Sweileh WM, Abu Arrah EM, Abu-Taha AS, Sawalha AF, Salah OA, Jamous RM, et al. Pharmacists' Dispensing Practices, Attitudes and Knowledge towards Herbal Products in Palestine. Ibnosina J Med Biomed Sci. 2013; 5(3): 123-130.

15. Mathew E, Muttappallymyalil J, Sreedharan J, John LJ, John J, Mehboob M, et al. Self-Reported Use of Complementary and Alternative Medicine among the Health Care Consumers at a Tertiary Care Center in Ajman, United Arab Emirates. Ann Med Health Sci Res. 2013; 3(2): 215-219.

16. Al-Arifi MN. Availability and needs of herbal medicinal information resources at community pharmacy, Riyadh region, Saudi Arabia. Saudi Pharm J. 2013; 21(4): 351 360 .

17. Cuzzolin L, Benoni G. Safety Issues of Phytomedicines in Pregnancy and Paediatrics. In: Ramawat KG, editor.
Herbal Drugs: Ethnomedicine to Modern Medicine: Springer Berlin Heidelberg; 2009; pp 381-396.

18. Essential Medicines and Health Products Information Portal (A World Health Organization resource). [Cited 2017 Jan 6]. Available from: http://apps.who.int/ medicinedocs/en/d/Js7916e/9.3.html.

19. Ventola CL. Current Issues Regarding Complementary and Alternative Medicine (CAM) in the United States: Part 2: Regulatory and Safety Concerns and Proposed Governmental Policy Changes with Respect to Dietary Supplements. P \& T. 2010; 35(9): 514-522.

20. Department of Health and Medicines and Healthcare products Regulatory Agency Rotrohmap, 2015 [Cited 2017 Jan 6]. Available from: https://www.gov.uk/ government/uploads/system/uploads/attachment_data/fil e/417768/Report_on_Regulation_of_Herbal_Medicines_ and_Practitioners.pdf.

21. American Herbalists Guide, An association of herbal practitioners, AHG guide to getting an herbal education [Cited 2017 Jan 22]. Available from: http://www.americanherbalistsguild.com/herbal_educatio $n$.

22. The National Institute of Medical Herbalists NIMH Accreditation [Cited 2017 Jan 6]. Available from: http://www.nimh.org.uk/?page_id=2161. 